\title{
BMJ Open Suitability of a three-dimensional model to measure empathy and its relationship with social and normative adjustment in Spanish adolescents: a cross-sectional study
}

\author{
Mauricio Herrera-López, ${ }^{1}$ Olga Gómez-Ortiz, ${ }^{2}$ Rosario Ortega-Ruiz, ${ }^{2}$ \\ Darrick Jolliffe, ${ }^{3}$ Eva M. Romera ${ }^{2}$
}

To cite: Herrera-López M, Gómez-Ortiz 0, OrtegaRuiz $\mathrm{R}$, et al. Suitability of a three-dimensional model to measure empathy and its relationship with social and normative adjustment in Spanish adolescents: a crosssectional study. BMJ Open 2017;7:e015347. doi:10.1136/ bmjopen-2016-015347

- Prepublication history for this paper is available online. To view these files, please visit the journal online (http://dx.doi org/10.1136/bmjopen-2016015347).

Received 29 November 2016 Revised 15 August 2017 Accepted 23 August 2017

\section{CrossMark}

${ }^{1}$ Department of Psychology, University of Nariño, Pasto, Nariño, Colombia

${ }^{2}$ Department of Psychology, University of Córdoba, Córdoba, Andalucía, Spain

${ }^{3}$ Department of Criminology, University of Greenwich, Old Royal Navy College, London, UK

Correspondence to PhD Mauricio Herrera-López; mherrera@udenar.edu.co

\section{ABSTRACT}

Objectives (1) To examine the psychometric properties of the Basic Empathy Scale (BES) with Spanish adolescents, comparing a two and a three-dimensional structure;(2) To analyse the relationship between the three-dimensional empathy and social and normative adjustment in school. Design Transversal and ex post facto retrospective study. Confirmatory factorial analysis, multifactorial invariance analysis and structural equations models were used. Participants 747 students (51.3\% girls) from Cordoba, Spain, aged 12-17 years ( $M=13.8 ; S D=1.21)$.

Results The original two-dimensional structure was confirmed (cognitive empathy, affective empathy), but a three-dimensional structure showed better psychometric properties, highlighting the good fit found in confirmatory factorial analysis and adequate internal consistent valued, measured with Cronbach's alpha and McDonald's omega. Composite reliability and average variance extracted showed better indices for a three-factor model. The research also showed evidence of measurement invariance across gender. All the factors of the final threedimensional BES model were direct and significantly associated with social and normative adjustment, being most strongly related to cognitive empathy.

Conclusions This research supports the advances in neuroscience, developmental psychology and psychopathology through a three-dimensional version of the BES, which represents an improvement in the original two-factorial model. The organisation of empathy in three factors benefits the understanding of social and normative adjustment in adolescents, in which emotional disengagement favours adjusted peer relationships. Psychoeducational interventions aimed at improving the quality of social life in schools should target these components of empathy.

\section{INTRODUCTION}

\section{Empathy dimensions}

The study of empathy has predominantly been carried out from three study areas: neuropsychology, developmental psychology and social psychology. ${ }^{1}$ Every one of these scientific

\section{Strengths and limitations of this study}

- This paper could benefit the understanding and study of school violence given the offers an updated perspective of the study of empathy from three dimensions (cognitive empathy, emotional contagion and emotional disengagement), and its influence on social and normative adjustment in school.

- The application of rigorous analysis to test the relationships between study variables and for the analysis of the psychometric properties of the Basic Empathy Scale(confirmatory factorial analyses, structural equation models and multigroup factorial invariance analyses were used).

- This study acknowledges the need for longitudinal and cross-cultural studies to improve confidence in these results; likewise, the analysis could be limited by not having deepened the measurement of empathy in each dimension according to gender differences.

perspectives has significantly contributed to the configuration of the concept, in which at least three different cognitive-emotional processes are identified: (1) feeling what another person is feeling; (2) knowing how to interpret what the other person is feeling, that is, recognising his/her emotions and (3) showing interest in responding when facing the other person's emotion. ${ }^{12}$

The main theoretical contributions have recognised that empathy is a capacity that includes affective elements, which allow us to automatically react before the other person's emotion and cognitive elements, which implies understanding the other person's perspective, being this process more controlled and conscious. ${ }^{3-5}$

Studies of empathy have consistently demonstrated the use of examining both the cognitive and affective elements of empathy 
to better understand adolescent behaviour. ${ }^{67}$ In addition, gender is an essential aspect to consider in the studies of empathy at this age. Multiple studies show that women present higher levels of affective empathy than men. ${ }^{8}$ However, studies outline that the gender differences could be biased by the way of measuring this concept ${ }^{9}$ and also due to the cultural aspects, which has traditionally linked the most affective values to the female gender. ${ }^{10}$

Recent research suggests that the classical two-dimensional model of empathy (affective vs cognitive) may benefit from a reconceptualisation, ${ }^{11} 12$ which includes a third process based on the concept named by Decety and Jackson $^{2}$ as 'intention to respond to the others' emotion'.

The advances in neuropsychological and neuroimaging research show that empathy may be conceptualised into three components, each involving interacting, yet partially non-overlapping neural circuits. ${ }^{11} 13$ From this perspective, it seems to be more coherent to show a three-dimensional empathy construct made up of: (1) emotional contagion, which refers to the ability to experience others' emotional states, ${ }^{14}$ (2) cognitive empathy, which implies the ability to understand others' emotions and (3) emotional disengagement, the ability to avoid other people's emotions; perhaps as a form of self-protection against the anxiety generated by others' emotional states. ${ }^{15}$ Emotional contagion appears to be associated with subcortical structures such as the limbic system, which provides a rapid assessment of the valence of others' emotions (pleasant or aversive), essentially automatically, ${ }^{16}{ }^{17}$ and mirror neurons. This motor neurons are located in the premotor, motor and anterior intraparietal area and are activated when we do some movements if we are being watched by other people (eg, facial mimicry of basic emotional expressions). They contribute to share the affective world with the others from the first childhood. ${ }^{18}{ }^{19}$ However, this process of emotional contagion is not sufficient in the later developmental stages to understand the others' emotions. Empathy requires understanding those emotions and their development, which implies building a representation of them which allows us to be conscious of them without confusing them with ours. This sophisticated function which refers to the cognitive empathy lies on the mind theory and appears to involve activation of the insular cortex, the ventromedial prefrontal cortex (PFC) and the medial PFC. ${ }^{11}$ These phylogenetically recent structures which are more slowly developed than other brain areas reach their maturation at the end of adolescence or at the beginning of adulthood. Therefore, it is not until that moment that we can fully display the executive and regulation functions linked to them. The emotional disengagement, which completes the empathy construct, plays an essential role to display an adaptive empathetic response because it is an ability which avoids the fact that an extreme emotional affectation occurs compromising our welfare. It is located in the orbitofrontal cortex, the medial and dorsolateral prefrontal cortex and the anterior cingulate cortex. Its full power is reached in later developmental stages. ${ }^{13}$
The emotional regulation has been proved to be the affective process which allows to combine the previous empathic dimensions, being involved to an extent in others' emotion and managing to understanding it, but without causing high levels of stress or discomfort. ${ }^{20}$ From a developmental point of view, the processes related to emotional contagion are the first to appear. Later, as age and brain maturation progress, other cognitive and emotional regulation functions are developed (cognitive empathy and emotional disengagement); all are related to the executive functions and to the development of the theory of the mind, acquired at later ages. ${ }^{21-23}$

On the other hand, a three-factor empathy model can offer certain potential benefits to differentiate between primary and secondary psychopathy. Both forms of psychopathy are associated with severe antisocial behaviour, and the empathic deficits are one of the most proffered causes. For primary psychopaths, these deficits appear to be limited to affective empathy, with cognitive empathy being at normal levels, thus the psychopath's glib and superficial charm but inappropriate affect. ${ }^{24}$ In contrast, secondary psychopaths are characterised by affect instability and anxiety, which is not well accounted by a two-factor conceptualisation of empathy. ${ }^{25}$ However, using a three-factor model, secondary psychopaths could have sufficient cognitive empathy and emotional contagion but more limited abilities to emotionally disengage; thus anxiety occurs, being overwhelmed with others' emotions. There is clearly explanatory power in further exploring this proposed 'new' factor structure of empathy, as this could contribute to a more coherent understanding of the relationship between empathy and this and other antisocial and prosocial behaviours.

\section{Measurement of multidimensional empathy}

One instrument which could accommodate this new conceptualising of the definition of empathy ${ }^{4}$ is the Basic Empathy Scale (BES). ${ }^{5}$ This device has shown good psychometric properties and is one of the most widely used in Europe. Although there are other instruments that are commonly used to measure empathy in adolescents, this scale is the only one that has been originally developed using this population. The items on this scale were selected based on four of the five 'basic emotions' (fear, sadness, anger, happiness) and it has been validated in a number of countries using samples of varying ages including children from France ${ }^{26}$ and Spain $^{27}$; preadolescents from Slovakia ${ }^{28}$ and a combination of adolescents and adults from France, ${ }^{21} 29$ Italy, ${ }^{30}$ Portugal, ${ }^{31}$ China,, 233 Singapore, ${ }^{34}$ El Salvador, ${ }^{35}$ Peru ${ }^{36}$ and Spain. ${ }^{37}$ Although appropriate psychometric properties were observed in these baseline studies and the two-factor structure proposed by the authors was an evidence (cognitive empathy and affective empathy), recent research using a French sample showed optimal results using an alternative structure, with the reorganisation of the items into the three factors. ${ }^{2126}$ A further potential benefit of this study is that Spanish is one of the most widely used languages in 
the world; therefore, a new three-dimensional version of the BES-translated and validated in Spanish-could be a significant contribution to the study of empathy in the many Spanish-speaking countries.

\section{Three-dimensional empathy and social and normative adjustment}

There is growing interest in the study of empathy and its potential associations with the development and maintenance of peer relations. ${ }^{38}$ This is because studies continue to demonstrate that empathy is positively associated with psychosocial adjustment ${ }^{21} 39$ and negatively associated with aggressive behaviours such as bullying and cyberbullying. ${ }^{274041}$ For example, greater levels of empathy have been associated with an increased likelihood of self-reported prosocial behaviour among school-aged children. ${ }^{5}$ However, there is limited research in studies considering empathy from a three-factor conceptualisation.

Clearly, a more comprehensive understanding of the relationship between the three factors of empathy and social behaviour is warranted. This includes examining how empathy and its constituent parts might relate to social and normative adjustment in schools. Social adjustment refers to the degree to which a person engages in socially competent behaviours adaptive to the immediate social context, ${ }^{42}$ and normative adjustment refers to the ability to align behaviour with social conventions and norms that guarantee respect towards the others. ${ }^{43}$ This collection of attitudes and behaviours (eg, cooperation, solidarity, mutual acceptance, respect) are key components of a good collective school climate. ${ }^{4344}$

This study presents two aims: (1) to analyse the psychometric properties of the BES in a large sample of Spanish adolescents and compare the three-factor structure (shown to be the best in studies conducted with non-Spanish adolescents) with the two-factor structure (the only factorial structure tested with Spanish populations); (2) to examine the associations between empathy and social and normative adjustment in school.

The hypotheses of this study were: (1) the three-factor structure will show better psychometric properties than the two-factor structure, showing invariance across gender and (2) cognitive empathy will show the strongest association with both social and normative adjustment.

\section{MATERIALS AND METHODS}

\section{Study design}

The study was a cross-sectional design, ex post facto, retrospective study with one group and multiple measures. ${ }^{45}$

\section{Participants}

The sampling was incidental, selected under the following criteria of accessibility: permission given by the educational centre and geographical proximity for a better displacement. According to statistical requirements, to carry out an instrument validation, it is necessary to have at least 400 participants in total. ${ }^{46}$ Thus, four educational centres of Córdoba, Andalusia, southern Spain, were chosen, where all the students took part. The public and private character of the centres was controlled so that they were represented in the sample, so half of the selected centres belonged to every simple type of school. The final sample was composed by 747 Spanish adolescents (51.3\% girls). They were students of secondary education (high school) and were aged between 12 and 17 years $(M=13.84$, $\mathrm{SD}=1.22)$.

\section{Instruments}

Empathy was measured with the BES. ${ }^{5}$ This scale has 20 Likert-type items with five possible responses ( $1=$ strongly disagree to 5 =strongly agree), originally organised into two dimensions: cognitive empathy (nine items) and affective empathy (11 items). ${ }^{5}$ Additionally, we used the threefactor version that redistributes the original elements by organising them in: emotional contagion (six items), cognitive empathy (eight items) and emotional disengagement (six items). ${ }^{21}$ Higher scores indicate higher levels of empathy.

To measure social adjustment, which refers to the degree to which a person engages in socially competent behaviours adaptive to the immediate social context, the Social Adjustment Scale was applied. This presents nine Likert-type items, with seven possible responses ( $1=$ strongly disagree to $7=$ strongly agree). An example item for the social adjustment scale is: 'My classmates are interested in me'. ${ }^{43}$ To measure the normative adjustment, which refers to the ability to align behaviour with conventions and social norms that guarantee respect for others, the Normative Adjustment Scale was applied. This contains five Likert-type items, also with seven possible responses $(1=$ strongly disagree to $7=$ strongly agree). An example item for the social adjustment scale is: 'I ask as a question and wait for an answer before I speak' ${ }^{43}$ Higher scores indicate higher levels of social and normative adjustment. These two last scales were created and validated in a study on multidimensional social competence in educated Spanish adolescents. ${ }^{43}$

\section{Procedure}

Permission of both school management teams and the expressed authorisation of the adolescents' familiesthrough informed and signed consent-were obtained. Adolescents were also informed that their participation was voluntary. The paper questionnaires were administered by trained researchers and were anonymous. The average completion time was $30 \mathrm{~min}$. The study was approved by the Biomedical Research Ethics Committee of Andalusia and developed in accordance with the considerations of the Declaration of Helsinki and the Spanish Society of Psychology.

Initially, the BES scale was translated into Spanish through the process of 'parallel back-translation'. ${ }^{47}$ The scale content was further validated using a pilot study with 60 students who assisted in assessing the degree of comprehension of each item. The students' proposed changes were incorporated into the final version. 


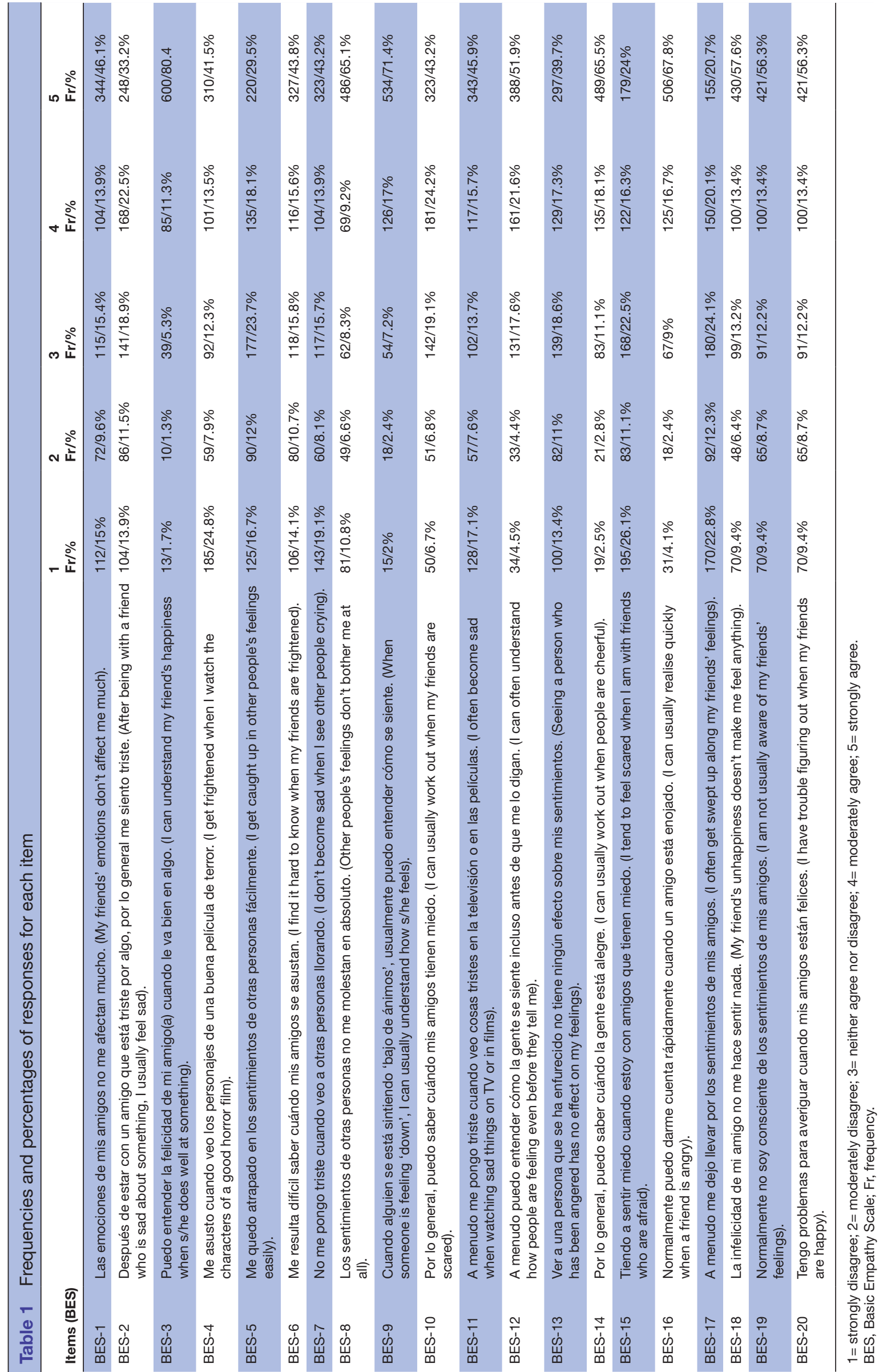




\begin{tabular}{|c|c|c|c|c|c|}
\hline \multirow{2}{*}{ Scale/Factor } & & \multicolumn{2}{|c|}{$\mathrm{n}=767$} & \multirow[b]{2}{*}{ Skewness } & \multirow[b]{2}{*}{ Kurtosis } \\
\hline & & $\mathbf{M}$ & SD & & \\
\hline Total empathy & & 3.86 & 0.59 & -0.29 & -0.51 \\
\hline Two factors & Cognitive empathy & 4.22 & 0.60 & -0.73 & 0.29 \\
\hline \multirow[t]{2}{*}{ Three factors } & Emotional contagion & 3.33 & 0.94 & -0.25 & -0.57 \\
\hline & Emotional disengagement & 3.89 & 1.00 & -0.80 & -0.12 \\
\hline Social adjustment & & 5.86 & 0.82 & -0.87 & 0.58 \\
\hline Normative adjustment & & 5.59 & 1.08 & -0.96 & 1.37 \\
\hline
\end{tabular}

\section{Analysis of data}

Questionnaires with missing data or those partially completed were removed. Eight per cent (64) of the data collected were lost. Only fully completed questionnaires were used (747).

To test the multivariate normality, the Mardia's coefficient was analysed using the $\mathrm{MVN}^{48}$ package in $\mathrm{R}$ program. ${ }^{49}$

Confirmatory factor analyses (CFA) and structural equation modelling (SEM) were performed using the EQS V.6.2 program. ${ }^{50}$ Given the categorical nature of the variables and the absence of multivariate normality, the estimation method of maximum likelihood was chosen with robust scaling ${ }^{51}$ and polychoric correlations. ${ }^{52}$ To assess the fit of the models the following indices were used: $\chi^{2}$ Satorra-Bentler $\left(\chi_{\mathrm{s}-\mathrm{B}}^{2}\right),{ }^{53}$ value significance $(\mathrm{p}>0.001), \chi^{2}$ party by the $\mathrm{df}\left(\chi_{\mathrm{S}-\mathrm{B}}^{2} / d f\right)(\leq 5)$, the Comparative Fit Index (CFI), the Non-Normed Fit Index (NNFI) $(\geq 0.90)$, the root mean square error approximation (RMSEA) $(\leq 0.08)$ and the standardised root mean-square residual (SRMR) $(\leq 0.08) .{ }^{54}$ The Akaike Information Criterion (AIC) was also evaluated to compare the obtained models, being lower values more desirable.

Given the fact that it was necessary to recognise the factorial stability of the instrument (three-dimensional $\mathrm{BES}$ ) from the measures and differences of empathy according to gender, a multifactorial invariance analysis was performed. This kind of testing includes a number of sequential analyses with progressively restricted models. Four different models were tested: model 1, where the same factor structure is imposed on the two groups (configural invariance); model 2, where covariances are constrained to be equal across groups; model 3, where factor loadings are constrained to be equal across groups (metric invariance) and model 4, where factor loadings and covariances are constrained to be equal across groups (residual invariance). The $\chi^{2}$ difference test $\left(\Delta \chi_{\mathrm{s} \text { - }}^{2}\right.$ ${ }_{\mathrm{B}}$ ) was used to test the invariance degree. Non-significant changes in $\chi^{2}$ suggest intergroup invariance. ${ }^{4755}$ Delta $(\Delta)$ differences between the adjustment indicators (NNFI, IFC, RMSEA and SRMR) were also considered. The cut-off point suggested in the literature to accept the hypothesis of invariance across groups is a change of $0.01 .^{56} \mathrm{~A}$ multigroup analysis was performed using EQS V.6.2. ${ }^{50}$

In addition to calculated the Cronbach's alpha $(\alpha)$, the McDonald's Omega ( $)^{57}$ was used to estimate the internal consistency of the instruments $(\alpha / \geq 0.60)$ given that the variables were categorical and reflected the absence of multivariant normality. ${ }^{58}$ The analysis was performed using the Factor V.9.2 programme. ${ }^{59}$ Moreover, to estimate the construct reliability, composite reliability (CR) and the average variance extracted (AVE) were computed. The cut-off points for these indices are 0.70 and 0.50 , respectively. Discriminant validity was also examined by comparing the AVE of the pairs of latent variables to the shared variance-square of the correlation between the pairs of variables. If the first indicator was higher than the last indicator, the questionnaire would be considered as having shown good discriminant validity. ${ }^{60}$ The adopted level of significance was 0.05 .

\section{RESULTS}

\section{Psychometric properties of BES}

First, descriptive statistics were established for each item and dimension (see table 1 and table 2). The Mardia analysis showed a skewness coefficient of 57.38, $p<0.001$ and a kurtosis coefficient of $544.83, p<0.01$, indicating non-compliance with the assumption of multivariate normality.

The CFA of the original two-factor structure of the BES (cognitive empathy, emotional empathy), demonstrated appropriate fit, $\chi_{\mathrm{S}-\mathrm{B}}^{2}=839.355 ; \chi_{\mathrm{S}-\mathrm{B}}^{2} /(169)=4.967$; $p<0.001 ; \mathrm{NNFI}=0.904 ; \mathrm{CFI}=0.915 ; \mathrm{RMSEA}=0.069 \quad(90 \%$ CI 0.063 to 0.075 ); $\mathrm{SRMR}=0.088$; $\mathrm{AIC}=968.962$. In addition, the structure of the three-factor solution (emotional contagion, cognitive empathy, emotional disengagement) showed a CFA with good fit and indicators, $\chi$ $2_{S-\mathrm{B}}^{2}=618.163 ; \quad \chi_{\mathrm{S}-\mathrm{B}}^{2} /(167)=3.702 ; \quad p<0.001 ; \quad \mathrm{NNFI}=0.919 ;$ CFI $=0.929 ; \quad$ RMSEA $=0.063 \quad(90 \%$ CI 0.058 to 0.069$)$; $\mathrm{SRMR}=0.077$; $\mathrm{AIC}=284.163$ (see figure 1). Internal consistency values were adequate for both the two-factor model: $\alpha_{\text {affective-empathy }}=0.70 ; \alpha_{\text {cognitive-empathy }}=0.67$; $\Omega_{\text {affective-empathy }}=0.76 ; \quad \Omega_{\text {cognitive-empathy }}=0.71$ and the threefactor model: $\alpha_{\text {emotional-contagion }}=0.66 ; \quad \alpha_{\text {cognitive-empathy }}=0.69$; 


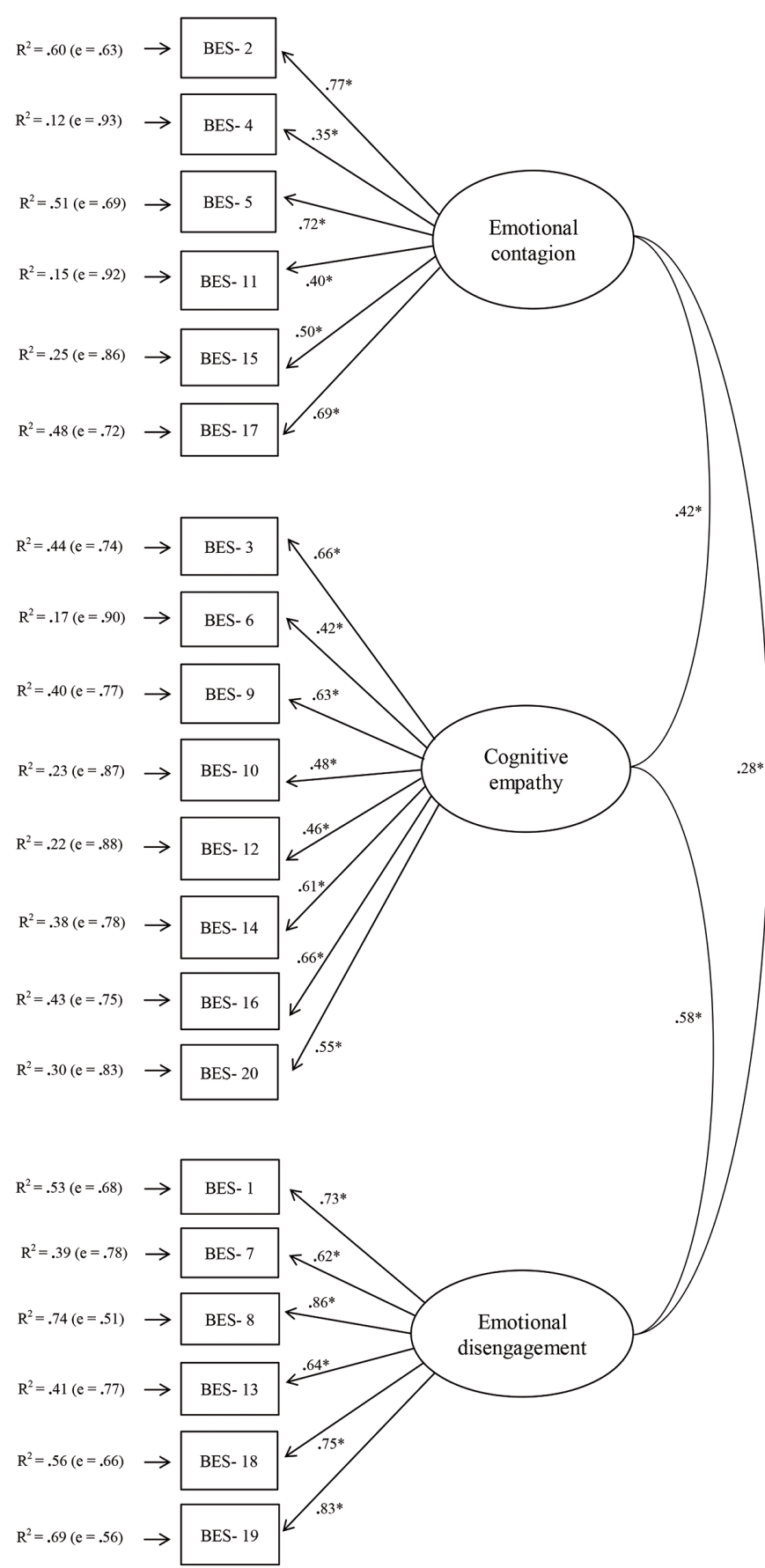

Figure 1 Confirmatory factor analysis -BES- of three factors. ${ }^{*} p<0.05$; BES, Basic Empathy Scale. $\alpha_{\text {emotional-disengagement }}=0.80 ; \quad \Omega_{\text {emotional-contagion }}=0.82 ; \quad \Omega_{\text {cognitive-em- }}$
pathy
$=0.71 ; \Omega_{\text {emotional- disengagement }}=0.80$.

The CR analysis showed inadequate values below the cut-off points for the two-factor BES, whereas for the three-factor model, the values were suitable for each factor (see table 3). Regarding the AVE, the values were not adequate for the two-factor model. However, in the three-dimensional model, the values of emotional contagion and cognitive empathy ranged from 0.33 to 0.55 , which are below the established cut-off points, although they are higher than the SC values (see table 3).
Table 3 CR, AVE and square correlations (below the diagonal)

\begin{tabular}{|c|c|c|c|c|c|}
\hline \multirow{2}{*}{$\begin{array}{l}\text { Factor/ } \\
\text { Dimension }\end{array}$} & \multicolumn{2}{|c|}{$\begin{array}{l}\text { BES two } \\
\text { dimensional }\end{array}$} & \multicolumn{3}{|c|}{ BES three dimensional } \\
\hline & AE & CE & EC & CE & ED \\
\hline $\mathrm{CR}$ & 0.69 & 0.63 & 0.71 & 0.75 & 0.83 \\
\hline AVE & 0.21 & 0.17 & 0.36 & 0.34 & 0.55 \\
\hline SC & \multicolumn{2}{|c|}{ AE-CE $\left(0.68^{\star \star}\right)$} & $\begin{array}{l}\text { EC-CE } \\
\left(0.18^{\star \star}\right) \\
\text { EC-ED } \\
\left(0.08^{\star \star}\right)\end{array}$ & $\begin{array}{l}\text { CE-ED } \\
\left(0.33^{\star \star}\right)\end{array}$ & - \\
\hline
\end{tabular}

${ }^{* *} p<0.01$.

$A E$, affective empathy; AVE, average variance extracted; BES, Basic Empathy Scale; CE, cognitive empathy; CR, composite reliability; EC, emotional contagion; ED, emotional disengagement; $\mathrm{SC}$, square correlations.

CFA results of BES by gender were distributed in three factors with adequate values, for both boys: $\chi_{\mathrm{S}-\mathrm{B}}^{2}=406.162$; $\chi_{\mathrm{S}-\mathrm{B}}^{2} /(167)=2.408 ; \quad p<0.001 ; \quad \mathrm{NNFI}=0.901 ; \quad \mathrm{CFI}=0.909$; $\mathrm{RMSEA}=0.067(90 \%$ CI 0.059 to 0.076$) ; \mathrm{SRMR}=0.080$; $\mathrm{AIC}=72.162$ and girls: $\chi_{\mathrm{S}-\mathrm{B}}^{2}=371.461 ; \chi_{\mathrm{S}-\mathrm{B}}^{2} /(167)=2.224$; $p<0.001$; NNFI=0.933; CFI=0.941; RMSEA=0.059 (90\% CI 0.051 to 0.067$)$; $\mathrm{SRMR}=0.077 ; \mathrm{AIC}=37.461$.

The results of the multigroup analysis were adequate. $\chi^{2}$ differences were non-significant between models 11 and 3 and between models 1 and 4. Changes on CFI, NNFI, RMSEA and SRMR were minimal between all the models (see table 4). These results show evidence of measurement invariance across gender groups. ${ }^{5455}$

The CFA of the Social Adjustment Scale showed adequate fit for the Spanish sample: $\chi_{\mathrm{S}-\mathrm{B}}^{2}=126.338 ; \chi$ ${ }_{\mathrm{S}-\mathrm{B}} /(27)=4.679 ; \quad p<0.001 ; \quad \mathrm{NNFI}=0.948 ; \quad \mathrm{CFI}=0.961$; $\mathrm{RMSEA}=0.079(90 \%$ CI 0.073 to 0.083$)$; $\mathrm{SRMR}=0.070$; $\mathrm{AIC}=122.339$. The internal consistency was adequate: $\alpha_{\text {social-adjustment }}=0.79 ; \Omega_{\text {social-adjustment }}=0.80$.

The CFA of the Normative Adjustment Scale also indicated adequate fit: $\chi_{\mathrm{S}-\mathrm{B}}^{2}=24.073 ; \quad \chi_{\mathrm{S}-\mathrm{B}}^{2} /(5)=4.815$; $p<0.001$; NNFI=0.982; CFI=0.991; RMSEA=0.034 (90\% CI 0.028 to 0.038$) ; \mathrm{SRMR}=0.040 ; \mathrm{AIC}=19.073$. The internal consistency was also adequate: $\alpha_{\text {normative-adjustment }}=0.79$; $\Omega_{\text {normative-adjustment }}=0.78$.

\section{Explanatory model}

We proposed a SEM in which empathy-organised into three factors-directly influenced social and normative adjustment. The analysis of polychoric correlations coefficients (PCC) between model variables showed moderate values between cognitive empathy and polychoric adjustment $(\mathrm{PCC}=0.40 ; p<0.01)$ and between cognitive empathy and normative adjustment $(\mathrm{PCC}=0.38 ; p<0.01)$. The final model (see figure 2) showed good fit indices, $\chi_{\mathrm{S}-}^{2}$ ${ }_{\mathrm{B}}=1544.337 ; \quad \chi_{\mathrm{S}-\mathrm{B}}^{2} /(521)=2.964 ; \quad p<0.001 ; \quad \mathrm{NNFI}=0.922 ;$ CFI $=0.931 ; \quad$ RMSEA $=0.056(90 \%$ CI 0.053 to 0.059$)$; $\mathrm{SRMR}=0.080 ; \mathrm{AIC}=502.377$. This indicated that emotional contagion was directly related to social adjustment $(\beta$ $=0.12 ; p<0.05)$ and normative adjustment $(\beta=0.05 ; p<0.05)$. 


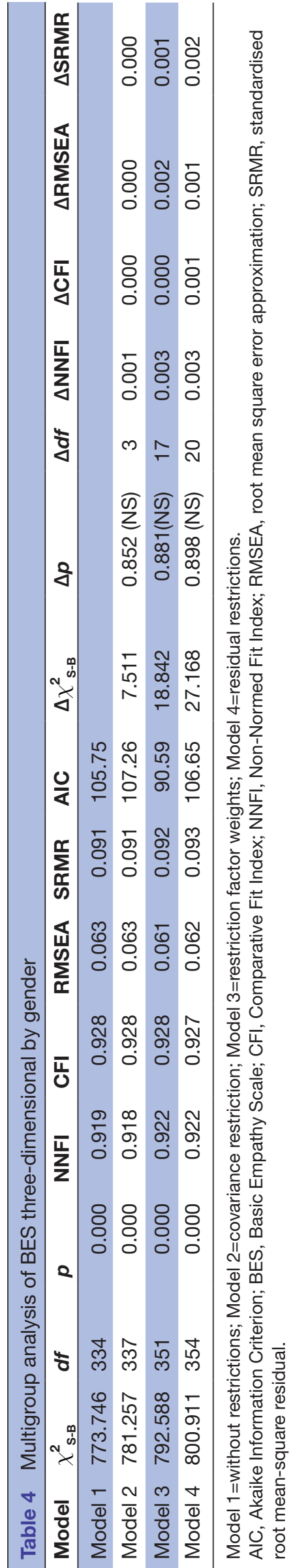

Cognitive empathy was also found to be directly related to both social adjustment $(\beta=0.61 ; p<0.05)$ and normative adjustment $(\beta=0.40 ; p<0.05)$. Finally, emotional disengagement was found to have a direct and negative influence on social adjustment $(\beta=-0.08 ; p<0.05)$ and a direct influence on normative adjustment $(\beta=0.07 ; p<0.05)$. Together these direct relationships accounted for $39 \%$ of the total variance of social adjustment and $17 \%$ of normative adjustment (see figure 2).

\section{DISCUSSION}

The first aim of this study was to analyse the psychometric properties of $\mathrm{BES}^{5}$ in a sample of Spanish adolescents, specifically to compare the two-factor structure (cognitive and affective empathy) with the three-factor structure (emotional contagion, cognitive empathy and emotional disengagement). This had not been previously examined in any Spanish sample. The results, when compared with those obtained in France ${ }^{2126}$ showed better psychometric properties for the three-factor version, compared with the original-and much more commonly used-two-factor structure. The evidence for this comes from numerous improvements in the adjustment NNFI, CFI, RMSEA, SRMR indices and the AIC index. In addition, the threefactor solution showed adequate values of internal consistency for all the factors. This was different Akaike low value reported for cognitive empathy of $\alpha=0.69$ with a French sample. ${ }^{21}$ When the composite reliability values were compared, better results were found for the threefactor structure in comparison to the two-factor structure, and although low values were obtained in the AVE in the dimensions of emotional contagion and cognitive empathy, these values exceeded those of the square of the correlations. ${ }^{60}$ Therefore, this suggests that this solution provides significantly better discriminant validity compared with the two-factor structure.

Unlike previous research using the BES and empathy more generally, this new conceptualisation allows to assess the extent to which an individual retreats from or does not engage in the emotional states of others, in addition to the more commonly assessed abilities related to emotional understanding (cognitive empathy) and emotional experience (emotional contagion). ${ }^{12} 15$ Finally, in contrast with the studies carried out in France which eliminated one ${ }^{21}$ and two items, ${ }^{26}$ this Spanish validated scale maintains all the items of the original design.

The analysis of the CFA for each gender, as well as the analysis of the factorial invariance indicated that the three-factor solution was optimal for the measurement of empathy for both men and women. Despite existing socialisation aspects which could contribute to a different self-perception of empathy between both genders, results indicate that both girls and boys actually understand this construct in the same way, which is important to delve into the understanding of the building process of emotional identity that female and male children must develop throughout their lives. ${ }^{61}$ 


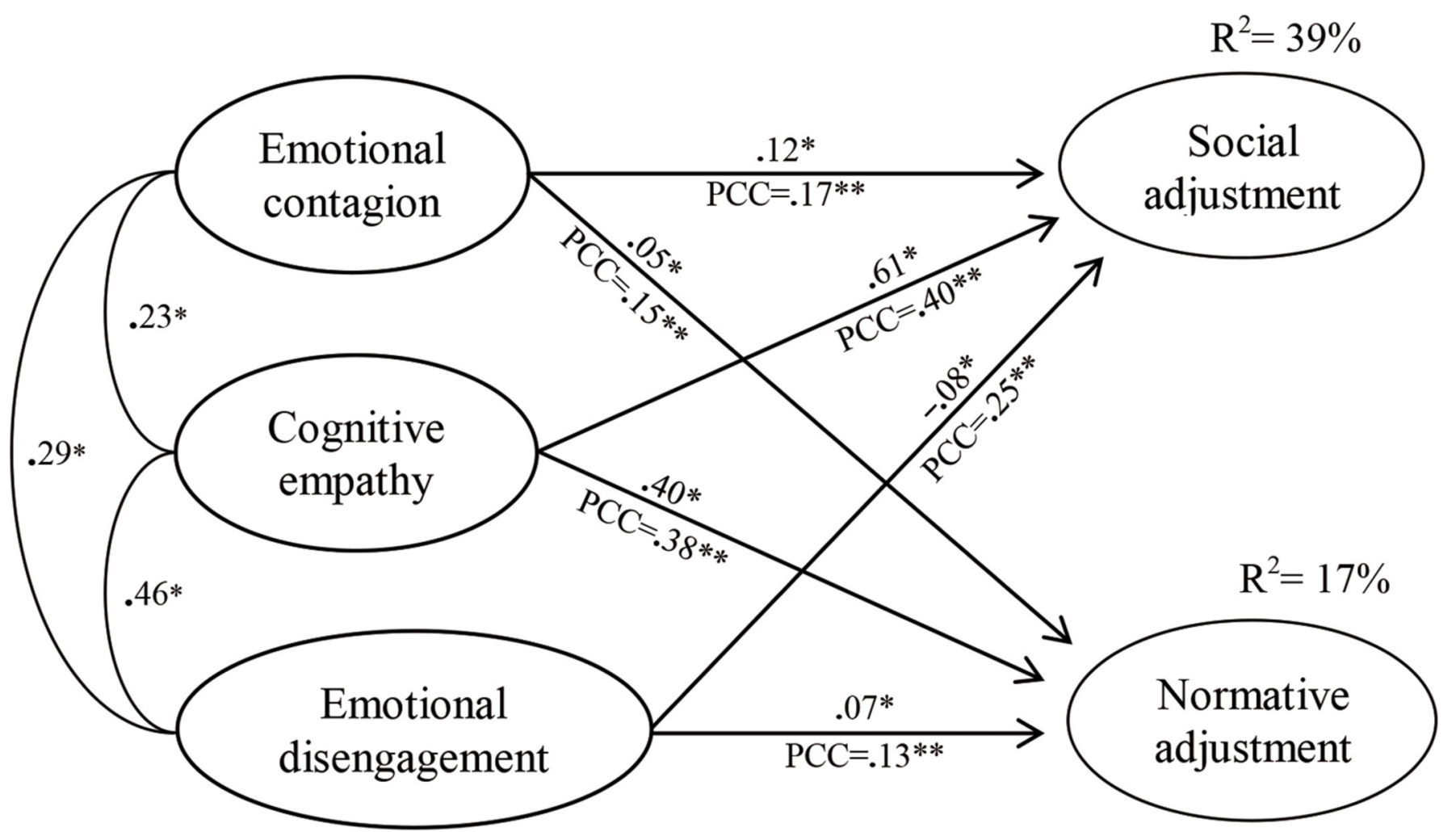

Figure 2 Structural equation modelling final. Relationship between empathy of three factors and social and normative adjustment. ${ }^{\star} p<0.05 ;{ }^{* \star} p<0.01$; PCC, polychoric correlations

The second objective of this study was to evaluate the magnitude of the relationship between the three identified dimensions of empathy and both social and normative adjustment. In general, the percentage of variance explained suggested that empathy was significantly associated with both of these forms of adjustment. The results of the final model suggested that cognitive empathy played a primary role. The relationship between emotional contagion and social adjustment was low but direct, but the relationship with emotional disengagement was low and inverse, indicating that higher levels of disengagementor failing to fully engage with the others' emotions-did not develop to optimal interpersonal relationships. ${ }^{62}$ However, it is important to consider the moral characteristics of the peer group. Aggressive groups could expect immoral actions from their members. In this case, emotional disengagement from peer's negative emotions (eg, anger, hostility), particularly those involved in recruitment for bullying for example, could facilitate prosocial behaviour when facing up considerable emotional peer pressure. In this case, emotional distancing could therefore benefit moral action.

The results also showed a direct relationship between cognitive empathy and normative adjustment. This could suggest that understanding others' emotions such as sadness, anger or fear facilitates compliance with school rules, perhaps because this ability facilitates a sense of connection and group cooperation. ${ }^{63}$ In other words, attitudes and behaviours such as respect for the others' opinions, waiting in turn to speak, letting others work and in general, engagement with social and normative conventions benefitted from increased levels of cognitive empathy. Cognitive empathy might benefit acceptance, respect and solidarity, favoring an improvement in social interactions and interpersonal relationships. Consequently, adolescents who understand others' emotions and understand the purpose of school rules are more likely to regulate their behaviour accordingly. ${ }^{64}$

Emotional contagion and emotional disengagement showed a low but direct association with normative adjustment. This suggests that although it may be necessary to be involved to some degree in the others' emotions (for example, feeling anger, sadness or fear when others experience these), it is also important to keep emotional distance. This may be beneficial for providing space to evaluate what behavioural responses are most appropriate, and at the same time it may allow some control over one's own emotional response. This affective space could offer the opportunity to interpret social situations more carefully when dealing with emotional experiences that could be potentially overwhelming.

In summary, this study suggested that a Spanish version of the BES structured into three factors measured empathy in adolescents more adequately and fit more coherently with what is known about emotional functioning from a psychological and neuropsychological point of view. In spite of the limitations that measuring a psychological construct through self-reports entail-due to the neuropsychological ability it implies-this research presents some strong points: on the one hand, it offers 
scientific evidence based on confirmatory, reliability, validity and factorial invariance analyses which support the suitability of measuring empathy from a three-factor model, following the recent contributions from neuropsychology, psychology and psychopathology. On the other hand, it allows us to have a Spanish version of the BES, which will foster its use in Spanish-speaking countries and which will allow a cross-cultural comparison. Furthermore, this work reaffirms the potential importance of strengthening these three components of empathy for improving the quality of peer relationships in school. ${ }^{64}$ That is, social adjustment appears to be related with the understanding of others' emotions, and to some extent, it seems to be involved or invested in these. On the other hand, normative adjustment appears to be related to the understanding of others' emotions and to the ability to strike a balance between being overwhelmed by the others' emotional experiences and being emotionally disengaged. This key result illustrates the potential importance of emotional regulation for both the emotional contagion and disengagement components of empathy, as possible ways to stimulate improved interpersonal relationships and the establishment of moral reciprocity. Emotional regulation and subsequent controls on contagion and disengagement could restrict the emergence of uncritical and risky attitudes towards the others' emotions, which have been found to be present among those involved in bullying and cyberbullying. ${ }^{65} 66$

This study also showed that empathy contributed to the development of a healthy school culture. It further suggests that individuals suffering from cyberbullying to understand each other's feelings may be more able to negotiate egocentric positions and achieve sufficient emotional distance to make decisions that best fit the group, in opposition to individual goals. Empathy also promotes critical judgements that prevent individuals from getting carried away by emotions such as anger or sadness, and also benefits the emergence of more satisfied perhaps less conflicted relationships in the classroom. Overall, it seems that better skills in understanding others' emotions foster interpersonal relationships, resulting in the prosocial behaviour necessary for better social life and school environment. ${ }^{64}$

Finally, having a better instrument with recognised and proven prosocial properties to assess the dimensions of empathy demonstrated to be related to optimal peer interpersonal relationships should help to guide the design and implementation of educational programmes. These ought to be aimed at promoting the identification of others' emotions and the emotional regulation, which appears to allow a certain affective distancing without becoming fully emotionally disengaged.

The limitations of the study are related to social desirability, the use of self-report questionnaires and the fact that the sample was selected based on convenience. All of these aspects could bias its results. This potential response bias was mitigated as far as possible by providing anonymity to the participants and by ensuring that they were aware their responses would not be connected with them. This should encourage honest responding. In addition, in the analysis of the psychometric properties of the three-factor BES, low values in the average variance were extracted for emotional contagion and cognitive empathy. The adequate values of the other parameters and the fact that this device has been validated with different participants and cultures suppose sufficient criteria of validity and reliability to support the adequacy of this scale for measuring empathy. In future research, it would be advisable to carry out cross-cultural and prospective longitudinal studies which would allow to consolidate the results obtained here in different samples, as well as to investigate whether empathy changes over time and whether these changes are associated with changes in social or normative adjustment.

Acknowledgements The authors acknowledge the invaluable participation of the study subjects.

Contributors MHL conceived the study, in consultation with EMR, OGO and ROR, who participated in its design, review and drafting of the manuscript. DJ authorized the use of the BES scale and reviewed and supported the drafting and final structure of the paper. All authors read and approved the final manuscript.

Funding This study was carried out within the framework of the following projects: projects PSI2016-74871-R and PSI2015-64114-R funded by the Spanish National I+D+i Plan and Project EDU2013-44627-P funded by the Spanish National I+D Plan.

Competing interests None declared.

Patient consent Obtained.

Ethics approval CE-UCO, Faculty of Education Sciences, Department of Psychology.

Provenance and peer review Not commissioned; externally peer reviewed. Data sharing statement № additional data are available.

Open Access This is an Open Access article distributed in accordance with the Creative Commons Attribution Non Commercial (CC BY-NC 4.0) license, which permits others to distribute, remix, adapt, build upon this work non-commercially, and license their derivative works on different terms, provided the original work is properly cited and the use is non-commercial. See: http://creativecommons.org/ licenses/by-nc/4.0/

(c) Article author(s) (or their employer(s) unless otherwise stated in the text of the article) 2017. All rights reserved. No commercial use is permitted unless otherwise expressly granted.

\section{REFERENCES}

1. Davis MH. Empathy a social psychological approach. Boulder CO: Westview, 1996.

2. Decety J, Jackson PL. The functional architecture of human empathy. Behav Cogn Neurosci Rev 2004;3:71-100.

3. Davis MH. Measuring individual differences in empathy: evidence for a multidimensional approach. J Pers Soc Psychol 1983;44:113-26.

4. Cohen D, Strayer J. Empathy in conduct-disordered and comparison youth. Dev Psychol 1996;32:988-98.

5. Jolliffe D, Farrington DP. Development and validation of the Basic Empathy Scale. J Adolesc 2006;29:589-611.

6. Van Lissa CJ, Hawk ST, Meeus WH. The effects of affective and cognitive empathy on adolescents' behavior and outcomes in conflicts with mothers. J Exp Child Psychol 2017;158:32-45.

7. Vossen HGM, Piotrowski JT, Valkenburg PM. The longitudinal relationship between media violence and empathy: was it sympathy all along? Media Psychol 2016:1 -19.

8. Hawk ST, Keijsers L, Branje SJ, et al. Examining the (IRI) among early and late adolescents and their mothers. J Pers Assess 2013;95:96-106. 
9. Joseph DL, Newman DA. Emotional intelligence: an integrative metaanalysis and cascading model. J Appl Psychol 2010;95:54-78.

10. Toussaint L, Webb JR. Gender differences in the relationship between empathy and forgiveness. J Soc Psychol 2005;145:673-85.

11. Decety J. Dissecting the neural mechanisms mediating empathy. Emot Rev 2011;3:92-108.

12. Decety J, Svetlova M. Putting together phylogenetic and ontogenetic perspectives on empathy. Dev Cogn Neurosci 2012;2:1-24.

13. Decety J, Michalska KJ. Neurodevelopmental changes in the circuits underlying empathy and sympathy from childhood to adulthood. Dev Sci 2010;13:886-99.

14. lacoboni M, Dapretto M. The mirror neuron system and the consequences of its dysfunction. Nat Rev Neurosci 2006;7:942-51.

15. Lamm C, Batson CD, Decety J. The neural substrate of human empathy: effects of perspective-taking and cognitive appraisal. $J$ Cogn Neurosci 2007;19:42-58.

16. Derntl B, Finkelmeyer A, Eickhoff S, et al. Multidimensional assessment of empathic abilities: neural correlates and gender differences. Psychoneuroendocrinology 2010;35:67-82.

17. Phillips ML, Drevets WC, Rauch SL, et al. Neurobiology of emotion perception I: the neural basis of normal emotion perception. Biol Psychiatry 2003;54:504-14.

18. Decety J, Meidenbauer KL, Cowell JM. The development of cognitive empathy and concern in preschool children: a behavioral neuroscience investigation. Dev Sci 2017:e12570.

19. Rizzolatti G, Craighero L. The mirror-neuron system. Annu Rev Neurosci 2004;27:169-92.

20. Diamond A. Normal development of prefrontal cortex from birth to young adulthood: cognitive functions, anatomy, and biochemistry. In: Stuss DT, Knight RT, eds. Principles of Frontal Lobe Function. New York: Oxford University Press, 2002:446 -503.

21. Carré A, Stefaniak N, D'Ambrosio F, et al. The Basic Empathy Scale in adults (BES-A): factor structure of a revised form. Psychol Assess 2013;25:679-91.

22. Goldstein TR, Winner E. Enhancing empathy and theory of mind. $J$ Cogn Dev 2012;13:19-37.

23. Völlm BA, Taylor ANW, Richardson P, et al. Neuronal correlates of theory of mind and empathy: a functional magnetic resonance imaging study in a nonverbal task. Neuroimage 2006;29:90-8.

24. Jolliffe D, Murray J. Low Empathy and Offending. In: Loeber R, Welsh BC, eds. The future of criminology. Oxford: Oxford University Press, 2012:62-70.

25. Yildirim BO. A treatise on secondary psychopathy: psychobiological pathways to severe antisociality. Aggress Violent Behav 2016;31:165-85.

26. Bensalah L, Stefaniak N, Carre A, et al. The Basic Empathy Scale adapted to French middle childhood: structure and development of empathy. Behav Res Methods 2016;48:1 11

27. Sánchez-Pérez N, Fuentes LJ, Jolliffe D, et al. Assessing children's empathy through a Spanish adaptation of the Basic Empathy Scale: parent's and child's report forms. Front Psychol 2014;5:1438

28. Čavojova V, Sirota M, Belovičova Z. Slovak validation of the Basic Empathy Scale in pre-adolescents. Stud Psychol 2012:195-208.

29. D'Ambrosio F, Olivier M, Didon D, et al. The Basic Empathy Scale: a French validation of a measure of empathy in youth. Pers Individ Dif 2009;46:160-5.

30. Albiero P, Matricardi G, Speltri D, et al. The assessment of empathy in adolescence: a contribution to the Italian validation of the "Basic Empathy Scale.". J Adolesc 2009;32:393-408.

31. Pechorro P, Ray J V, Salas-Wright CP, et al. Adaptation of the Basic Empathy Scale among a Portuguese sample of incarcerated juvenile offenders. Psychol Crime Law 2015:7.

32. Geng Y, Xia D, Qin B. The Basic Empathy Scale: a Chinese validation of a measure of empathy in adolescents. Child Psychiatry Hum Dev 2012;43:499-510.

33. Li C, Lv R, Liu J, et al. The adaptation of Basic Empathy Scale among Chinese adolescents. Chinese J Clin Psychol 2011:163-6.

34. Ang RP, Goh DH. Cyberbullying among adolescents: the role of affective and cognitive empathy, and gender. Child Psychiatry Hum Dev 2010;41:387-97.

35. Salas-Wright CP, Olate R, Vaughn MG. Assessing empathy in Salvadoran high-risk and gang-involved adolescents and young adults: a Spanish validation of the basic empathy scale. Int $J$ Offender Ther Comp Criminol 2013;57:1393-416.

36. Merino-Soto C, Grimaldo-Muchotrigo M. Validación estructural de la escala básica de empatía (Basic Empathy Scale) modificada en adolescentes: un estudio preliminar. Rev psicol 2015;24:261-70.

37. Villadangos M, Errasti J, Amigo I, et al. Characteristics of empathy in young people measured by the Spanish validation of the Basic Empathy Scale. Psicothema 2016;28:323 9.
38. Blanke ES, Rauers A, Riediger M. Does being empathic pay off? Associations between performance-based measures of empathy and social adjustment in younger and older women. Emotion 2016;16:671-83.

39. Allemand M, Steiger AE, Fend HA. Empathy development in adolescence predicts social competencies in adulthood. J Pers 2015;83:229-41.

40. Casas JA, Del Rey R, Ortega-Ruiz R. Bullying and cyberbullying: Convergent and divergent predictor variables. Comput Human Behav 2013;29:580-7.

41. van Noorden TH, Haselager GJ, Cillessen AH, et al. Empathy and involvement in bullying in children and adolescents: a systematic review. J Youth Adolesc 2015;44:637-57.

42. Crick NR, Dodge KA. A review and reformulation of social information-processing mechanisms in children's social adjustment. Psychol Bull 1994;115:74-101.

43. Gómez-Ortiz O, Romera-Félix E-M, Ortega-Ruiz R. Multidimensionality of social competence: measurement of the construct and its relationship with bullying roles. Revista de psicodidáctica 2017;22:37-44.

44. Cialdini RB, Reno RR, Kallgren CA. A focus theory of normative conduct: recycling the concept of norms to reduce littering in public places. J Pers Soc Psychol 1990;58:1015-26.

45. Montero I, León OG. A guide for naming research studies in psychology. Int J Clin Heal Psychol 2007;7:847-62.

46. Lloret-Segura S, Ferreres-Traver A, Hernández-Baeza A, et al. El análisis factorial exploratorio de los ítems: una guía práctica, revisada y actualizada. An Psicol 2014;30:1151-69.

47. Muñiz J, Elosua P, Hambleton RK. Psicothema. Directrices para la traducción y adaptación de lostests: segunda edición. International test commission guidelines for test translationand adaptation. 2nd ed, 2013:151-7.

48. Kormaz S, Goksuluk D, Zararsiz G. Mutivariate normality tests: package "MVN". 2015 http://www.biosoft.hacettepe.edu.tr/MVN/

49. Team RDC. R: a language and environment for statistical computing. Manual y software de cómputo, 2008.

50. Bentler RM, Ej W. EQS for windows. [Statistical program for windows]. 2012.

51. Bryant FB, Satorra A. Principles and practice of scaled difference chi-square testing. Struct Equ Model a Multidiscip J 2012;19:372-98.

52. Morata-Ramírez María de los Ángeles, Holgado-Tello FP. Construct validity of likert scales through confirmatory factor analysis: a simulation study comparing different methods of estimation based on pearson and polychoric correlations. Int J Soc Sci Stud 2013;1:54-61.

53. Satorra A, Bentler PM. A scaled difference chi-square test statistic for moment structure analysis. Psychometrika 2001;66:507-14.

54. Hu Li-tze, Bentler PM. Cutoff criteria for fit indexes in covariance structure analysis: conventional criteria versus new alternatives. Struct Equ Model a Multidiscip J 1999;6:1-55.

55. Bollen KA. Structural Equations with Latent Variables. New York: Wiley, 1989.

56. Dimitrov DM. Testing for factorial invariance in the context of construct validation. Meas Eval Couns Dev 2010;43:121-49.

57. Revelle W, Zinbarg RE, . Coefficients alpha, beta, omega and the GLB: comments on sijtsma. Psychometrika 2009;74:145-54.

58. Elosua OP, Zumbo BD. Coeficientes de fiabilidad para escalas de respuesta categórica ordenada. Psicothema 2008;20:896-901.

59. Lorenzo-Seva U, Ferrando PJ. Factor: a computer program to fit the exploratory factor analysis model. Behav Res Methods 2006;38:88-91.

60. Hair J, Black W, Babin B, et al. Multivariate data analyses. 6th Ed. Nueva York: Prentice-Hall, 2005.

61. Zajdel RT, Bloom JM, Fireman G, et al. Children's understanding and experience of mixed emotions: the roles of age, gender, and empathy. J Genet Psychol 2013;174:582-603.

62. Chow CM, Ruhl H, Buhrmester D. The mediating role of interpersonal competence between adolescents' empathy and friendship quality: a dyadic approach. J Adolesc 2013;36:191-200.

63. Boor-Klip HJ, Segers E, Hendrickx MM, et al. The moderating role of classroom descriptive norms in the association of student behavior with social preference and popularity. J Early Adolesc 2015:27.

64. Barr JJ, Higgins-D'Alessandro A. Adolescent empathy and prosocial behavior in the multidimensional context of school culture. $J$ Genet Psychol 2007;168:231-50.

65. Brewer G, Cyberbullying KJ. self-esteem, empathy and loneliness. Comput Human Behav 2015;48:255-60.

66. van Langen MAM, Wissink IB, van Vugt ES, et al. The relation between empathy and offending: A meta-analysis. Aggress Violent Behav 2014;19:179-89. 